Ruch, T. C. \& Watts, J. W. (1933). Am. F. Physiol., I05, 86.

SCARFF, J. E. \& PoOL, J. L. (1946). F. Neurosurg., 3, 285.

ShERrington, C. S. (I947). The Integrative Action of the Nervous System. Second Ed. New Haven: Vale Univ. Press.

\title{
Discussion
}

F. W. MeINECKE (Germany). May I make one suggestion? There is a big confusion, especially amongst the accident surgeons, between the two terms, spinal shock and traumatic shock, and I think it would be worth while to give a definition of the term spinal shock and to publish it in the paper so that we can tell the people what we mean.

Sir Ludwig Guttmann (G.B.). I am glad about this question. The spinal shock must not be confused with the general traumatic shock. In spite of some resemblances, such as fall of blood pressure in cord lesions above $\mathrm{Th}_{5}$, there are fundamental differences. The reflex depression in spinal shock in the isolated cord area is just as profound in distal thoracic cord transection where the blood pressure is not reduced. The disturbed blood circulation due to traumatic shock can be restored but this has no, or only insignificant, influence on the reflex depression due to spinal shock. Moreover, reflex depression of the isolated cord is equally profound whether the anterior spinal artery is severed or not. Therefore, spinal shock represents an independent phenomenon from the disturbed blood circulation due to traumatic shock.

H. L. Frankel (G.B.). I should like to thank the two main speakers, whose efforts I greatly enjoyed this morning. However, I would like to ask them (presumably they do not know or they would have told us by now) the mechanism of spinal shock. Perhaps they could make one or two intelligent guesses, just to keep us further interested. I would, as a clinician, like to know what are the mechanisms or substances. I would like to give the antidotes from the start, because I would like to get the sphincters working quicker and I also would like to avoid the alarming vagal overactions we sometimes get. We have heard today mainly about what spinal shock isn't. Would either of the openers like to go further into some of the possible mechanisms that are involved.

Professor Ascoli (Italy). I should be very thankful to Sir Ludwig if he could tell us something about the return of sensibility and of vesical function after spinal shock. It is of practical interest.

P. Doll Fus (France). I am called by the Colmar Traumatology Unit to see patients within about $\frac{3}{4}$ to I hour after injury, which is most interesting. Being a pupil of Sir Ludwig's, naturally I examine the patient fully (laughter). I say fully because some neurological examinations in these traumatic lesions are not done. One case has appeared to be very interesting. It was a young man of 18 with a complete lesion below C4. This boy never ceased passing his urine with an automatic bladder. We found urine on his clothes when he was admitted-I was rather surprised by this fact, although it has been described. Afterwards, he always had $100 \mathrm{cc}$. to I $50 \mathrm{cc}$. residual urine but his bladder remained automatic all the time. Also, furthermore, he had never stopped having an anal reflex. I have found the anal reflex very early, being practically the only reflex present until the others developed.

P. HARRIS (G.B.). I would like, like the others, to congratulate our two speakers. I would like to know about the terms 'spinal concussion' and 'spinal shock'. These terms are terribly important to all of us, because of the obvious physiological and clinical con- 
cepts. These terms are not synonymous. Can we distinguish one from another immediately or early in the situation in man? The question of the flexor plantar responses being present is interesting and was touched upon by Sir Ludwig. How can this occur in a complete transection of the spinal cord? I wonder about partial transections of the cord such as following antero-lateral cordotomy. This does not, of course, stop reflexes. Can we learn something there? Regarding DOPA, I wonder about DOPA metabolism in spinal shock, is it disturbed and if so in what way and to what type of DOPA is Professor Phillips referring? We are using DOPA for dyskinesia, but this, we feel, is for rigidity. One does not want to get mixed up, at least clinically, between rigidity and spasticity. These are some comments.

J. Garcia-Alsina (Spain). My first question is when can we diagnose the ending of spinal shock. According to Fulton maybe a reflex which was previously depressed or absent is starting again, if that is enough to say that spinal shock has ended. A remark I would like to make is that I was particularly interested in this subject of spinal shock and that maybe is the reason why I came here. I have no new ideas after what I have heard this morning.

J. ForNER (Spain). I would like to ask a question: What happens when an hemiplegic gets a complete paraplegia, what is the reflex pattern in the sound side and the affected side?

D. Hancock (G.B.). I would like Professor Phillips to comment of Ellis's work. Apparently it has been found that when the cord in the cat, I believe, is de-afferented the terminal buttons disrupt or disappear and return in about three months' time. Can you tie that in with the clinical physiology that we find with return of reflex function?

D. Cheshire (Australia). I have two observations which lead to questions. The first is-I think it is - the common observation of many of us that a patient admitted and examined, Dr. Dollfus properly! - may be found to have a present anal reflex and a flexor plantar response. There was a time when we were taught that any persistent reflex activity below the level of the lesion indicated that the lesion was not complete, and I would be interested to hear an explanation which satisfies me, I haven't yet heard it, why these two reflexes persist in a patient who, in fact is and remains completely paralysed. The second observation relates to Professor Guttmann's statements concerning the patient who soon after spinal cord injury had an ascent of his lesion. If I did not misinterpret Sir Ludwig, in almost one sentence he used the term spinal shock and spinal concussion. I wonder if, in fact, under these circumstances, we might be dealing neither with spinal shock not spinal concussion but with traumatic oedema of the distal cord.

J. VERNON (G.B.). I just mention an observation I have often made with, say, a mid-thoracic lesion who comes in who is complete, you go over the muscle power of the upper limbs and you find that very weak. I am just wondering whether this was just psychological. You may say the patient has had a lot of bashing and those muscle weaknesses will recover in a day or two, or is it in fact some question of spinal shock above the lesion which up to date has escaped clinical observation? I just leave that as an observation which I have made. One thing I have often found is that the bulbo-cavernosus reflex is positive almost as soon as the patient comes in but I seldom ever find the anal reflex positive.

G. M. Pool (The Netherlands). I would like to put a question to Professor Phillips on muscle tone. Sir Charles Sherrington states that an animal does not need tone when it's asleep, it only needs tone when it wakens. I wonder if it is known how it is with the tone in spinal animal with transection of the cord: is there also a difference in tone when it is asleep and when it is awake? 
J. SiLVER (G.B.). I would like to thank the two speakers for their excellent papers. One thing worries me about Professor Phillips's wonderful exposition, that I didn't see a manuscript. I only hope that it will be recorded in Paraplegia as it was given, for us to study in due course. To come to some of the points that Paul Dollfus and Vernon have been made about the anal reflex, I have been making regular observations on admissions of the patients and I think you can divide patients into two groups. There is the majority of patients with complete lesions who have a positive anal reflex on admission but there are some, a very small number-I have only seen it in about one or two caseswho have an absent anal reflex on admission and which subsequently returns after a period of days. With regard to the point that was made by Dr. Vernon about the bulbocavernosus reflex being present and the anal absent, I haven't made regular observations on this, but I believe Bors makes a point that the bulbo-cavernosus is a more powerful reflex and if you are going to get any reflex at all you will get a bulbo-cavernosus, whereas the anal may be absent. But, I would be most interested to know from our two speakers the mechanism of this preservation of the flexion of the toes on admission and how it subsequently becomes extensor, because I have seen this on many occasions, and I know it was recorded in Riddoch's paper in I9I7, but I haven't seen any explanation as to how it occurs. I have read Kugelberg's accounts of it, but again it did not help me. The points raised about the phenomena seen above the level of the cord transection, I think Sherrington and Schiff described in fact an enhancement of the reflexes above the level of the cord transection, where one finds brisk tendon reflexes in the arms above the level of the cord transection, the Sherrington-Schiff phenomenon-I have seen this, in the later stages. The question of the weakness that one might find occasionally, could this be related to Jousse and Botterell's work, where you find these toothpaste extrusions of material extending to a much higher level of the cord following a cord transection?

J. Benassy (France). An interesting point in cord sections is I think the fact that venous blood becomes red-i.e. that levels of oxygen $\mathrm{CO}_{2}, \mathrm{pH}$, the alkaline reserve are nearly the same as in the arterial blood supply. It is a phenomenon that lasts as long as the cord has not recovered and probably it is the basic cause of many of the phenomena that we can observe in each organ.

G. BRUNo (Italy). Do you think immediate surgical treatment can aid the resolving of the spinal shock? (Laughter.)

CHAIRMAN. If there are no more questions or comments we will ask our speakers to start with the difficult job of clarifying everything that has been raised.

Professor Phillips (G.B.). I am afraid this is not possible. What is shock? If you could cut the cord across clean, without any haemorrhage, without any oedema above or below, without a discharge of impulses at the instant of injury, upwards and downwards if that were possible, then I would say that in the segments below the level of this absolutely clean cut the reflexes would be changed in some of the kinds of ways that I have tried to illustrate from the research of the school in Gothenburg. I think a physiologist would prefer to say there is not a single condition of spinal shock from which it could be said that an individual had recovered at some particular time, but rather that all the reflex patterns present in those segments were disturbed in different directions, some completely switched off, inaccessible to the normal stimuli from the normal receptive fields, others abnormally excitable from abnormally large receptive fields, as the thing gradually changes as days and hours succeed the lesion. But, of course, in what I was talking about I was dealing only with the acute stage, because the work on different stages of recovery is not very far advanced. So, I would say that to a physiologist we can't say that there is a single condition but we can say that it is an altered balance of reflexes in the segments below a lesion, but in your practice this must always be complicated by the fact that the 
lesion is not clean, it is probably extending up and down a few segments, temporarily by oedema, certainly by haemorrhage and bruising and that there will also be an abnormal discharge of impulses in injured fibres which may continue perhaps-as even in peripheral nerves Adrian showed that an injury can go on causing a discharge of impulses for about 30 hours after crushing of a nerve. So that it is not a clear cut and a clean thing but I think that what the physiologist is talking about in the general term shock is, of course, that these segments are cut off from the brain. They are just never going to be accessible to control again, because the central nervous system doesn't regenerate. But, then, below this level, what is happening to the reflexes of the segments. They are all abnormal at first, some of them absolutely lost.

Taking the questions not in the order they were asked, I remember in Holmes's first report of gunshot wounds of the spinal cord from the first war he drew attention to the presence of a very feeble plantar reflex within the very earliest hours after injury and this anal reflex that Dr. Dollfus was telling you about and others have mentioned in the discussion is perhaps another of these, but we simply don't know why these particular things may survive in the particular circumstances of the injury. If I could just come to the end of what I would like to say, now, before answering all the other questions, which seem to arise out of what I am trying to say. I was terribly impressed-and have been before reading Sir Ludwig's findings-about what happens in the hours and days and weeks after the injury and how you can modify it by altering the position of limbs and so on. One must remember that from the first the skin and other receptor organs are all there still, and it should be possible to discover particular areas of skin that you should stimulate every day. It's not just perhaps a matter of passively putting the joints through their movements but saying to get that reflex going I am going to stimulate that particular receptive field every day. Now, this obviously can be done by stroking the skin, but you need to know what areas to stroke. If you wish to develop the stretch reflexes of particular muscles then the new methods of vibration that have been introduced into clinical neurology should be re-weighed for selectively exciting the primary endings in the muscle spindles. If you could do this to particular groups of muscles and find out how their reflex arcs reacted to this treatment from the earliest hours-I think that this is the kind of suggestion that the physiologist, if he isn't regarded as too impertinent, ought to be making to you. You have the skin and the muscles there from the moment of injury, and you may be able to influence what is going to happen in the spinal cord cut off from brain control by putting in systematically certain afferent influence. And that goes on to the question I was asked about Dr Ellis's work. No doubt, disuse will cause degeneration of synapes, and therefore to prevent that you ought to be keeping inputs coming to them.

On muscle tone in sleeping and waking, there is no doubt that the sensitivity of the muscles to lengthening of the discharge that comes back from a muscle held at any particular length is dependent on the activity, of the fusomotor neurons which control sensitivity of that spindle. And there is no doubt that the particular formation in sleeping and waking alters very much this activity, particularly of the static fusomotor neurons, so that an animal which is asleep has very little fusomotor activity and therefore a muscle held at a particular length will be sending much fewer impulses back to the central nervous system, having very much less effect on the motor neurons and interneurons, than it would be if the fusomotor system were active, as it is in an alert animal, and very much more activity would be coming back from the muscle receptors. I hope that is some part of the answer to your question. The DOPA I mentioned was Levo 34. It is clear already from what I have said from the work on DOPA that there is a nor-adrenotic transmission to the static gammas, but of course those synapses have to be there for this injection of DOPA to have any effect, and this experiment has only been done in the acute stage. I imagine that injection of DOPA into a chronic animal when these synapses have degenerated would have no effect. But this again is waiting to be done, so far as I know. 
Sir Ludwig Guttmann (G.B.). Well we have had a bouquet of very excellent questions. I should like to discuss first the disappearance of the static reflexes following interruption of the vestibulo-spinal and reticulo-spinal pathways. Of course, in complete cord transections, they are cut off completely and there is no regeneration of the spinal cord. However, the fact remains that in the later stages after cessation of spinal shock new static reflexes can be developed in the spinal man, provided you develop as early as possible those muscle groups which are responsible for posture, by means of certain stimuli, mentioned in my paper which promote extensor responses. I am glad that, in this respect, we can teach the physiologists something about the patho-physiology of the spinal man as they have taught us about that in the spinal cat or dog. Therefore, the old concept that the spinal man cannot stand is no longer valid.

Sherrington found in some dogs following cord transection a preponderance of extensor rigidity instead of the expected preponderance of the flexion synergy once the isolated cord had recovered from spinal shock. His explanation was that 'some incidental circumstance determining the preponderance of some passive attitude of the limb during the early days succeeding the lesion may, by its influence on the interaction of the recovering spinal arcs, impress an unwanted reflex habit upon the limb'. It was exactly that observation which was the initiative to my own studies in the spinal man how far this 'unwanted reflex habit' could be utilised to develop static reflexes to restore posture, standing and walking. I cannot go into details here how this was achieved by adequate positioning of the paralysed legs and passive movements during the stage of spinal shock. This has been described in 1953 in my monograph. In this process of re-adjustment, co-operate muscle groups such as latissimus dorsi and abdominals which have their segmental supply above the transection but on the other hand have their attachment in the paralysed area, especially the pelvis. Take a case of complete transection of the cord below Tio as an example. There are muscle groups such as latissimus dorsi and rectus abdominis which still on account of their segmental innervation and anatomical attachment connect the paralysed part of the body with the brain. If you send impulses from these muscles into the paralysed area you can then produce static reflexes and in this way reconnect the paralysed part of the body with the brain. Visual guidance during balancing exercises in front of a mirror are necessary to develop such impulses which through the optic system release the adequate effector responses to the afferent volleys which arise from the movement of the pelvis and are mediated along the innervation of the muscles just mentioned into the brain. That sounds perhaps too simple but it is a fact, how through such compensatory mechanisms in our organism a new scheme of posture can be developed.

The question was raised about the significance of the presence of certain reflexes immediately after transection of the spinal cord. A very important point. After transection you may find as a result of stimulating the sole some flexion of the toes, sometimes even a dorsi-flexion, immediately. This many people have thought to be a sign of an incomplete lesion of the spinal cord. It is not. Immediately after the transection the nervous energy of these particularly distal segments is still there and the electrical energy of the ganglion cells in these segments still responds to a strong stimulus at least for a certain time. It has been known for a long time that if a man is decapitated, for instance, he still maintains for a certain time his knee- and ankle-jerks. This has been found as early as 1915 by the French neurologist Barré. As the French still had the guillotine, that excellent apparatus to decapitate quite cleanly, the neurologist had the opportunity to investigate this problem. (Laughter.) Moreover, as I pointed out in my paper today, it has been found that in complete transection of the spinal cord areflexia of the kneejerk can be restored by faradisation for 5 or Io minutes. That was described in this country first by Collier in I9I6 and in Germany by Lewandowsky and Neuhoff (1915). I recall these findings of the old school of neurologists, to remind our younger colleagues of these findings, which in the light of modern reflexological research are of particular interest. I suggest that electrical stimulation of the extensor group of 
muscles should be carried out during spinal shock to promote early static reflexes in the spinal man.

Dr. Frankel has asked what is the mechanism of spinal shock. I can only repeat that there are quite a number of theories, as I mentioned in my paper. I can't go into all this, but one of the first theories was that of Goltz, that spinal shock was the result of an inhibition produced by irritation of the upper segments below the level of the lesion. This has not been proved correct. Modern concepts suggest that the areflexia in spinal shock is due to a decrease in sensitivity of muscle receptors to stretch as a result of fusimotor deficit and not due to decrease of excitability of the alpha motorneurons. One of the recent theories is that of Barnes (1964), who measured the resting membrane potentials of cells in the lumbar segments of the spinal cord in cats before, during and after functional block by cooling. They came to the conclusion that the physiological derangement in spinal shock is a hyperpolarization of motor neurons. This hyperpolarisation is considered as a result of the removal of random synaptic bombardment of nerve endings either directly or indirectly activated from more cephalad regions which normally keep the cells in a slightly hypopolarised state.

With regard to the return of reflexes, some investigators claim that the cremasteric reflex is one which recurs early. From the Tables, I have shown I can't confirm this statement. In fact, both the abdominal reflexes and cremasteric reflexes in high lesions come back, if at all, very late. However, there is another point. In certain cases of lesions, say $\mathrm{T}_{4}$, where all the abdominal muscles are paralysed, the abdominal reflexes may be elicited by a strong stimulus. This is exactly the same as I have explained with the positive toe flexion response immediately following cord transection. It is a local response, because the afferent stimulus is transmitted into the corresponding segments, where the segmental efferent response is elicited and that is the reason why the reflex is present.

With regard to the Sherrington-Schiff phenomenon, as mentioned by Dr. Silver, that has nothing to do with spinal shock whatsoever. This develops later, in the chronic animal, and as you may know I have described in the spinal man that in the peri-lesionary hyperactivity which occurs at and above the level of the lesion the sweat glands participate with all the other functions such as vasomotor and piloerection in the segments above the level of the lesion. This brings me to the interesting phenomenon of the triple response of Lewis. Lewis's view was that this is an entirely local reflex response. It may be so, but local phenomena can be altered by a lesion of the spinal cord.

That brings me to the question of the headwards effect of coid transection. As Professor Phillips quite rightly said, the experimental studies in animals are of course different from observation in the spinal man, but even so, if you have a clear cut knifeinjury you will find that above the level of the lesion there is some depression of function. Whether this is a concussional effect-I am sorry, that was a slip of my tongue-or the result of some circulatory changes immediately after the injury producing oedema is difficult to say as the functional depression in the areas above the transection soon disappears.

Dr. Forner asked a very interesting question, namely what happens if a hamiplegic gets a paraplegia. That is a point which has been examined by physiologists. Fulton and his colleagues have shown that if you produce in animal experiments a cerebral hemiplegia and cut the spinal cord after a certain time you will find the spinal shock on the opposite more marked than on the side of the hemiplegia, the reason being that in the meantime the intrinsic reflex activity below the cerebral lesion has already developed. In this connexion it is worth while mentioning that transections of the brain above the midpontine level do not produce reflex depression but on the contrary marked increase of reflex activity, namely decerebrate rigidity which leads to the conclusion that certain mechanisms in the proximal part of the brainstem counteract spinal shock.

I am sorry that one of the colleagues from Spain couldn't learn anything from this morning's papers, but I hope it will have made him think about certain points during this discussion. 
With regard to Dr. Ascoli's question of the effect of spinal shock on the bladder, this is a subject which will be discussed next year in detail. As you know after spinal cord transection there is only hyoptonia because the autonomous innervation within the bladder wall is still active and some effector response to afferent stimulation (distension) is possible. The bladder will only become atonic if it is allowed to overdistend-then you knock out the peripheral innervation. The overdistension of the bladder musculature produces an additional local effect to the effects produced already by the spinal cord transection, exactly as this occurs in the skeletal muscles. This applies also, of course, to the colon. In cervical cord lesions the immediate effect of cord transection is paralysis of the peristalsis resulting in intestinal distension due to meteorism which in turn has an adverse effect on the function of the diaphragm and thus on the impaired respiration, due to the paralysis of the intercostals. Dr. Silver and I have made extensive electro-myographic studies on the effect of spinal shock on the intercostal muscles published in Paraplegia in 1965. They participate, exactly as any other muscles in the reflex depression during spinal shock, but they also recover reflexly, and in due course, by a co-ordinated reflex function can help in the restoration of the vital capacity of the lung.

Finally, the very important question was asked whether an immediate surgical procedure in a traumatic paraplegia can aid in resolving spinal shock. You heard some laughter amongst the audience when this question was raised: the answer is NO! On the contrary, it just adds to the shock.

\title{
PROFFERED PAPERS
}

\author{
Chairman; Dr. T. GREGG
}

\section{IN DEFENCE OF THE FOSTER-STRYKER TURNING BED}

\author{
By Professor R. Ascoli \\ Milan, Italy
}

I DON'T know the name of the surgeon who said that practically all operating methods are equally satisfactory provided that they are used by an operator who is sufficiently well acquainted with them. I don't interpret this maxim literally, but it is true that there are surgeons and physicians who get excellent results with methods that others would describe as bad. And vice-versa. I would like today to say a word in defence of the turning beds of the Foster-Stryker type in the treatment of paraplegics. I am led to do this by the fact that today in the treatment of paraplegics and of bedsores there is a tendency to abandon the use of these beds for other methods of treatment, which in my view are far less reliable.

We are all acquainted with the principle of these turning beds: the purpose is to turn the bed about a longitudinal axis in such a way that the patient rotates en bloc with the plane on which he is lying, and in such a way that the slightest movement of the body, and in particular of the vertebral column, is impossible.

The chief indication of these beds are vertebral fractures with or without spinal cord lesions where it is of prime importance that the parts of the fracture remain completely immobile, and where it is also essential at intervals to change that part of the body-and in particular the skin-which supports the weight of the body. This aspect is clearly of great importance in the prevention and cure of bedsores: it affects in particular the sacral region, since here the skin is practically in contact with the bone surface underneath, and is especially exposed to ischemic and necrotic processes. 